\title{
Suicide, religion, and socioeconomic conditions. An ecological study in 26 countries, 1990
}

\author{
Jan Neeleman, Glyn Lewis
}

\begin{abstract}
Study objective-Relative risks are frequently assumed to be stable across populations but this may not apply in psychiatric epidemiology where sociocultural context may modify them. Such ecological effect modification will give curved associations between aggregated risk factor and outcome. This was examined in connection with the ecological association between suicide rates and an aggregate index of religiosity.

Design-Ecological study of associations between suicide rates and an index of religiosity, adjusted for socioeconomic variation. The effect of stratification of the study sample according to levels of religiosity, was examined.
\end{abstract}

Setting-26 European and American countries.

Subjects-Interview data from 37688 peope aggregated by country.

Outcome measures-Age and sex specific (1986-1990) suicide rates.

Main result-Adjusted for socioeconomic variation, negative associations of male suicide rates with religiosity were apparent in the 13 least religious countries only (test for interaction $F(1,25)=5.6$; $p=0.026)$. Associations between religiosity and female suicide rates did not vary across countries.

Conclusion-The bent ecological association was apparent only after adjustment for socioeconomic variation suggesting that, rather than confounding, ecological modification of individual level links between religion and male (but not female) suicide risk is the responsible mechanism. This concurs with micro-level findings suggesting that suicide acceptance depends not only on personal but also on contextual levels of religious belief, and that men are more sensitive to this phenomenon than women. In psychiatric epidemiology, relative risks vary with the exposure's prevalence. This has important implications for research and prevention. (F Epidemiol Community Health 1999;53:204-210)

Suicide rate variations remain poorly understood. Given rising trends internationally that remain unexplained, ${ }^{1}$ the search for macrolevel correlates of suicide remains as relevant as it was when Durkheim initiated it. $^{2}$ Suicide rate variations have been linked with local differences in unemployment, ${ }^{34}$ divorce, ${ }^{35}$ income levels, ${ }^{6}$ education, ${ }^{27}$ per capita alcohol intake, ${ }^{8}$ birth rates $^{9}$ and, repeatedly, religious characteristics. ${ }^{2} 671011$ However, findings are often contradictory.

In ecological research, the choice which countries or communities to study is governed by data availability more often than by a priori hypotheses. Suicide rates of American states, ${ }^{10}$ counties, ${ }^{11}{ }^{12}$ Canadian $^{13}$ or Dutch ${ }^{7}$ provinces, or Western European countries ${ }^{9}$ have all been studied in connection with religion. One study compared countries as different in religious context as Israel and Japan. ${ }^{6}$ The statistics used in these studies give linear associations between aggregate levels of risk or protective factors and suicide rates, implying fixed regression coefficients across the exposure range.

Inferences made from ecological associations may concern effects on group rates, but most often effects on individual risk. ${ }^{14}$ Thus, negative ecological associations between indices of religion and suicide rates are frequently taken to imply that, therefore, religious people are at lower risk of suicide than non-religious people. The slope of the regression line is, in such cases, used to calculate relative risks. ${ }^{15}$ However, cross level bias frequently invalidates conclusions concerning individual risks drawn from ecological patterns. ${ }^{14}{ }^{16}$ Even when ecological confounding, the first source of cross level bias, is controlled for, the possibility remains that the religious composition of individuals' countries modifies the risk they run given their personal levels of religiosity. It is with this contextuality, ecological effect modification, ${ }^{14}$ that this study is concerned.

Ecological effect modification implies, at the individual level, that relative risks are not constant but variable according to the risk factor's prevalence. It has received little attention presumably because relative risks, whose use originates in the epidemiology of chronic somatic disorder, are often assumed to be stable across populations. ${ }^{17}$ However, relative risks in social psychiatry are unlikely to be culture free. Churchgoing protects better against depression in religious compared with nonreligious communities. ${ }^{18}$ Unemployment is a stronger risk factor for suicidal behaviour when it is rare.$^{19}$ Positive life change predicts recovery from depression better in populations bereft of such events. ${ }^{20}$ Moreover, men may be more sensitive to such contextual effects than women. In contrast with suicide rates of women, those of men depend strongly on social and economical change. ${ }^{21}$ Levels of suicide tolerance in men, but not women, depend on beliefs prevalent locally, as much as on their personal convictions. $^{22}$

When present, a twofold ecological association exists between exposure prevalence and 
outcome numbers. Firstly, as in any ecological study, relative numbers of risk free and at risk persons vary with changing exposure prevalence. Secondly, rates of the outcome in these two groups will change when exposure prevalences vary. This implies that regression coefficients for the association between exposure and outcome should differ according to the prevalence of the exposure giving a curved or bent ecological regression line. This has been shown to apply to the association between regional indices of religiousness and suicide rates in the Netherlands. ${ }^{23}$

Against this background this study's purpose was to examine whether a bent regression line fits ecological associations of international suicide rates with indices of religion better than the straight line usually drawn in comparable studies. ${ }^{2}{ }^{6}{ }^{9-13}$ Ecological confounding, occurring when units of analysis differ in more aspects than the variable of interest only, may also affect the shape of the regression line and, when uncontrolled, increase or obscure curvilinearity because of ecological effect modification. ${ }^{16}$ Socioeconomic confounding was therefore adjusted for before examination of the shape of the regression line.

It remains disputed which aspects, if any, of religion are most relevant to health outcomes. Social integration may be the principal mediator of religion's beneficial effects on health ${ }^{24}$ but personal religious commitment, irrespective of social integration, may also be relevant. ${ }^{622} 25$ From data on religious affiliation, attendance, education and personal devotion, available from a large scale international survey conducted in $1990,{ }^{26}$ the strongest association of suicide rates was selected for further study.

The issue at stake, the contextual variability of relative risks in psychiatric epidemiology, has wide relevance. The inability of ecological researchers to agree on whether or not suicide rates are related to levels of, for instance, unemployment ${ }^{327}$ is likely to be simply because of the fact that such general questions cannot be answered. When unemployment is rife, it will be a weaker risk factor for suicidal behaviour than when it is $\operatorname{rare}^{19}$-this will strongly affect ecological patterns. The topic is also relevant for public health officials; reduction of the prevalence of risk factors whose individual level effect is subject to ecological effect modification, may concentrate the risk in the most vulnerable. ${ }^{28}$

\section{Methods}

SAMPLE

Countries were selected if (a) they had a Judaeo-Christian tradition, (b) they reported, in 1990, suicide and population counts to the World Health Organisation (WHO) using ICD-9 codes, and (c) World Values Survey (WVS) data were available for them. WVS was carried out by structured interview (375 items) on random population samples ( $>18$ years old) in 43 countries across the world ${ }^{26}$ to explore links between economic advance and individualisation. ${ }^{29}$ Stratified random sampling was used in most countries but in some, such as the USA, minority groups were oversampled.
Sampling weights, allocated to all respondents, allowed restoration of national samples' representativeness for international comparisons. ${ }^{26}$ Twenty seven countries met criteria (a) and (b) but Finland was excluded as computerised instead of face to face interviews were used there. ${ }^{29}$ The 26 countries included in the analysis (total $n=37688$ ) with sample sizes are given in the legend to table 2 .

VARIABLE PREPARATION AND AGGREGATION Religious variables

WVS contains items concerning religious affiliation (overall missing 95 of $37688=0.3 \%$; highest in Bulgaria; 28 of $1034=2.7 \%$ ) religious upbringing (overall missing 195 of $37688=0.5 \%$; highest in Sweden; 33 of $1047=3.2 \%$ ), frequency of church attendance (overall missing 824 of $37688=2.2 \%$; concentrated in Hungary 324 of $999=32.4 \%$ and Argentina 344 of $1002=34.3 \%$ ) ánd a series of 22 questions concerning personal beliefs and practices (for example, "Do you find comfort and strength from religion"). In Czechoslovakia, five questions only of the 22 had been asked. Excluding Czechoslovakia $(\mathrm{n}=1396)$, $3.4 \%$ (1244 of 36292 ) of respondents had missing scores on nine (40\%) or more of the 22 items with the highest missing rate in Poland (180 of $938=19.2 \%$ ). Eight of 1396 respondents in Czechoslovakia (0.6\%) had one or more missing scores. The 22 items were subjected to principal component (PC) analysis applied to the pooled dataset (weighted for sampling differences) yielding a main PC (religiosity) accounting for $48.8 \%$ of total item variance. Missing scores were imputed using best subsets regression giving values for all but one respondent. PC extractions of the 22 belief/practice items (five in the case of Czechoslovakia) were also run on national samples individually. The correlation between PCs based on these respective extraction methods was $0.88 ; p<0.001$. The correlation between the PC for Czechoslovakia based on its five items and the PC obtained for this country by imputation of values to the 17 missing items was 0.98 ; $p<0.001$. For individual countries, aggregate values for religious affiliation and religious upbringing were obtained by calculation of proportions. Aggregate values for religiosity and church attendance were obtained by calculation of national proportions of respondents scoring above the respective median for the pooled sample.

Suicide rates (/100 000)

For the period 1986-1990, average annual sex and age $(15-29,30-59,60+)$ specific rates of suicide, and suicide combined with undetermined death, were calculated using data obtained from WHO. ${ }^{30}$ Spearman's rank order correlation between suicide and combined suicide/undetermined death rates was 0.66 $(p<0.001)$. After exclusion of Chile, which uses the undetermined death category idiosyncratically, ${ }^{31}$ this rose to $0.93(\mathrm{p}<0.001)$. Given the large effect of Chile's undetermined death rates, suicide rather than combined suicide/ undetermined death rates were used further. 
Table 1 Crude ecological associations of the natural logarithm of sex and age specific suicide rates with religious and socioeconomic variables in 26 countries, 1986-90; standardised regression adjusted for national clustering of rates $(n=156)$

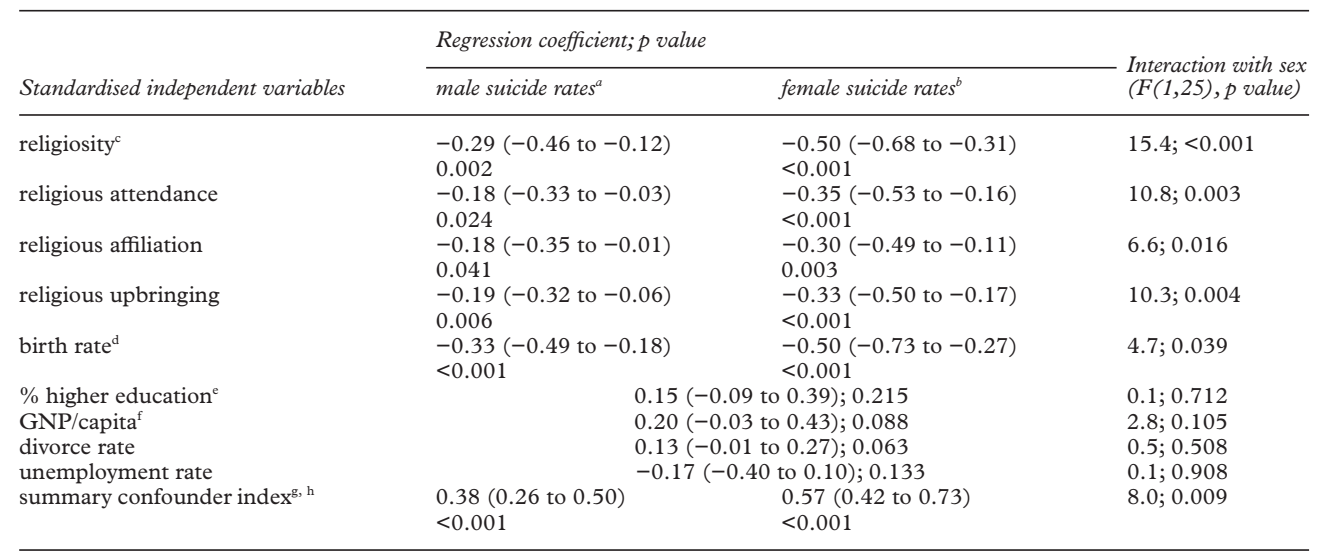

anly religiosity $(-0.45(-0.80$ to -0.09$) ; \mathrm{p}=0.017)$ contributed to a multivariate model containing all religious variables. Other variables: $F(3,25)=0.54 ; \mathrm{p}=0.659$. ${ }^{\mathrm{b}}$ Only religiosity $(-0.68(-1.01$ to -0.35$) ; \mathrm{p}<0.001)$ contributed to a multivariate model containing all religious variables. Other variables: $F(3,25)=0.62 ; \mathrm{p}=0.608$. ${ }^{\circ}$ Weighted for sample size men $-0.32(-0.51$ to -0.12$) ; \mathrm{p}=0.003$. Women $-0.53(-0.74$ to -0.33$) ; \mathrm{p}<0.001$. $^{\mathrm{d}}$ Unimputed $(\mathrm{n}=138)$ men $-0.33(-0.49$ to -0.16$)$. Women $-0.49(-0.73$ to -0.26$)$. ${ }^{\mathrm{e}}$ Unimputed $(\mathrm{n}=138) 0.16(-0.08$ to 0.40$)$. ${ }^{f}$ Unimputed $(\mathrm{n}=144) 0.21(-0.03$ to 0.45$)$. ${ }^{8}$ Unimputed $(\mathrm{n}=138)$ men $0.39(0.25$ to 0.53$)$. Women 0.60 (0.43 to 0.76$)$. hWeighted for sample size men 0.39 ( 0.29 to 0.50$) ; \mathrm{p}<0.001$; women 0.57 (0.41 to 0.73$) ; \mathrm{p}<0.001$.

Possible socioeconomic confounders

National birth rates, ${ }^{32}$ average income levels (in $\$ 1000$; GNP per capita), ${ }^{32}$ higher (>16 years) education enrolment levels, ${ }^{32}$ divorce, ${ }^{26}$ and unemployment rates $^{26}$ were obtained. For Iceland and Eastern Germany, birth, GNP, and higher education rates were unavailable.

\section{STATISTICAL ANALYSIS}

Least squares regression of logarithmically transformed male and female suicide rates was used. Independent aggregate variables were standardised to the entire aggregated dataset so that regression coefficients represent change in the outcome associated with one standard deviation's shift on independent variables. The effect of weighting for WVS sample sizes (to reflect higher precision of measures aggregated from larger samples) was assessed. ${ }^{33}$ When

Table 2 Associations of suicide rates, 26 countries, 1986-90, with religiosity before and after adjustment for socioeconomic confounding; standardised regression adjusted for national clustering of rates $(n=156)$

\begin{tabular}{|c|c|c|}
\hline Standardised independent variables & Male suicide rates & Female suicide rates \\
\hline \multicolumn{3}{|c|}{ Model unadjusted for socioeconomic confounding } \\
\hline religiosity & $-0.29(-0.46$ to -0.12$)$ & $-0.50(-0.68$ to -0.31$)$ \\
\hline (regression coefficient; p value) & 0.002 & $<0.001$ \\
\hline \multicolumn{3}{|l|}{ Interaction terms ( $F$ value; $\mathrm{df} ; \mathrm{p})$} \\
\hline religiosity ${ }^{\star}$ sample type $\mathrm{e}^{\mathrm{a}}$ & $F(1,25)=0.2 ; 0.646$ & $F(1,25)=0.02 ; 0.885$ \\
\hline \multicolumn{3}{|c|}{ Model adjusted for socioeconomic confounding } \\
\hline religiosity adjusted $^{\mathrm{b}}$ & joint sample & joint sample \\
\hline \multirow[t]{2}{*}{ (regression coefficient; $\mathrm{p}$ value) } & $-0.06(-0.22$ to -0.10$) ; 0.438$ & $-0.20(-0.38$ to -0.03$)$ \\
\hline & $\begin{array}{l}\text { sample } 1 \\
-0.34(-0.79 \text { to } 0.10) ; 0.118 \\
\text { sample } 2 \\
+0.17 \text { ( }-0.31 \text { to } 0.65) ; 0.456\end{array}$ & 0.025 \\
\hline \multicolumn{3}{|l|}{ Interaction terms ( $F$ value; df; $\mathrm{p})$} \\
\hline religiosity ${ }^{\star}$ age & $=0.014$ & $F(2,25)=4.6 ;<0.020$ \\
\hline religiosity ${ }^{\star}$ sample type ${ }^{a}$ & $F(1,25)=5.6 ; 0.026$ & $F(1,25)=1.4 ; 0.257$ \\
\hline
\end{tabular}

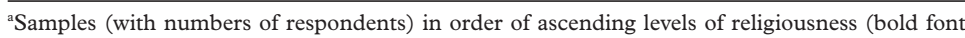
indicates abbreviations used in fig 1 ).

Sample 1 Sweden (1047), Bulgaria (1034), Eastern Germany (1336), Czechoslovakia (1396), France (1002), Norway (1239), Hungary (999), Netherlands (1017), Belgium (2792), West Germany (2101), England and Wales (1484), Spain (4147), Iceland (702).

Sample 2 Austria (1460), Portugal (1185), Canada (1730), Italy (2018), Romania (1103), Argentina (1002), Mexico (1531), USA (1839), Chile (1500), Northern Ireland (304), Brazil 1782), Ireland (1000), Poland (938).

${ }^{\mathrm{b}}$ Age adjusted estimates. Estimates unadjusted for age (fig 1) men (sample 1): $-0.57(-1.05$ to $-0.09)$. Men sample $2:+0.11(-0.39$ to 0.61$)$. Women $-0.24(-0.43$ to -0.05$)$.

$\star$ : interaction term. more than one rate per country was modelled-that is, when age was considered as a confounder (compare with age standardisation), Huber's adjustment of standard deviations was made to account for national rate clustering. ${ }^{34}$ Missing scores of socioeconomic confounders were imputed using best subsets regression $^{34}$; the effect of this was assessed by comparing regression coefficients before and after imputation

Firstly, crude associations were obtained by linear regression of male and female suicide rates on the separate religious and socioeconomic variables. Secondly, from a multiple regression model for suicide rates containing all religious variables, the best performing association of suicide rates was selected for further analysis. Thirdly, a regression was specified for suicide rates with the five socioeconomic confounders only as covariates. Using this model's coefficients, a summary confounder index was calculated for each country. ${ }^{33}$ Fourthly, associations of suicide rates with the best performing religious variable were adjusted for confounding, by controlling for the five separate socioeconomic variables jointly, and by using the summary confounder score instead. Finally, $F$ tests for interaction were used to assess whether associations of suicide rates with the religious variable differed between age groups and between countries scoring above and below the median for the religious variable.

\section{Results}

Negative associations were apparent between suicide rates and all four religious variables, most pronounced for religiosity and weakest for attendance and stronger for women and the elderly than for men and the young. Religiosity was selected for further analysis as this variable only contributed significantly to sex specific multiple regressions containing all religious variables (table 1). 


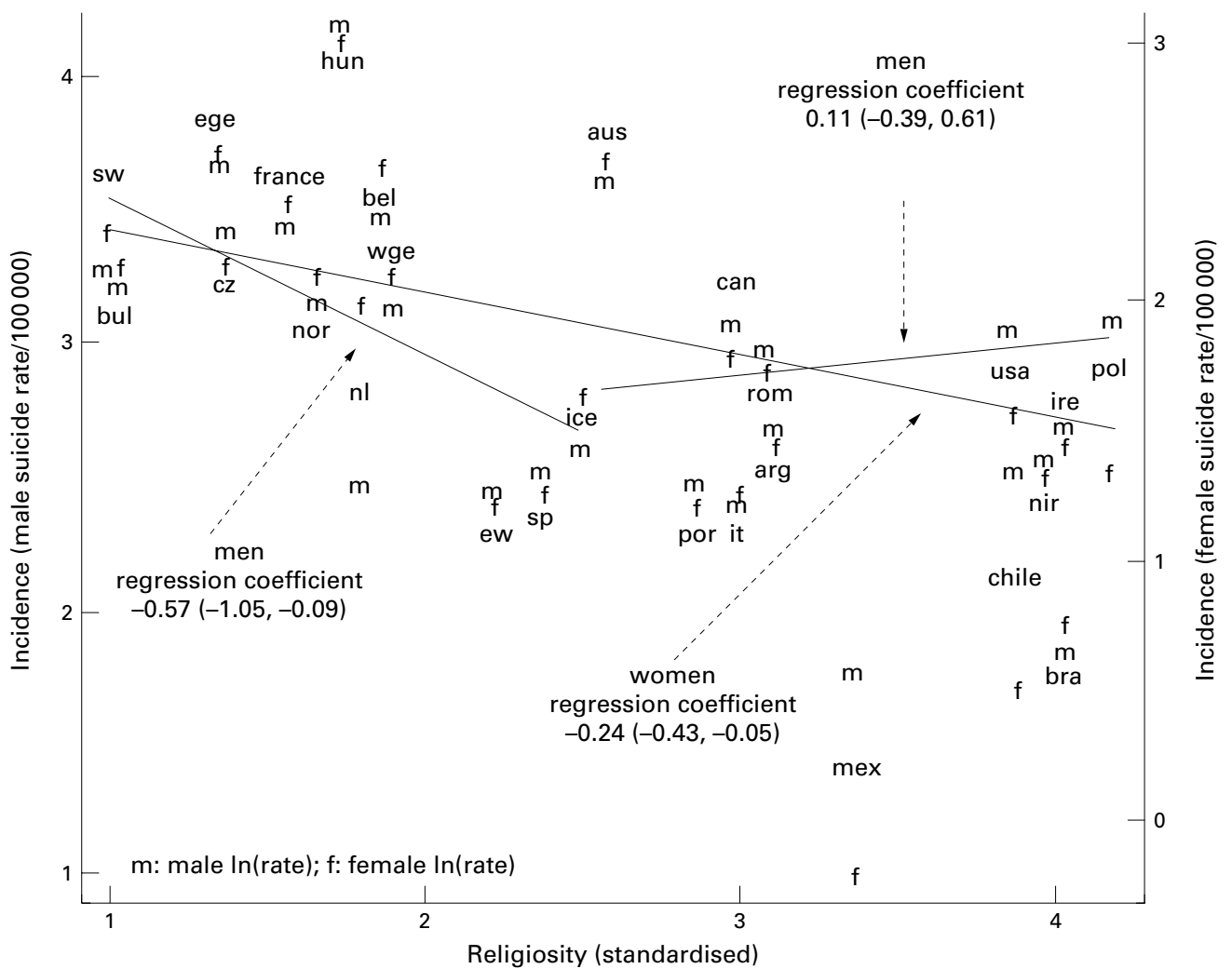

Figure 1 Male and female (crude) suicide rates by religiosity; regression lines adjusted for socioeconomic confounding.

Higher levels of enrolment in tertiary education, income levels, and divorce rates and lower unemployment rates were associations of higher suicide rates but none of them significantly so. Higher birth rates were associated with lower suicide rates but more so for women than men. Similarly, associations of suicide rates with the summary confounder index, capturing information on all five confounders, were stronger with female than male suicide rates. Size and statistical significance of these associations were hardly affected by missing value imputation or by weighting for WVS sample sizes (table 1).

Full adjustment using the separate socioeconomic indices removed the association of religiosity with male but not female suicide rates. For both sexes, the link between religios- ity and suicide rates depended on age irrespective of adjustment for socioeconomic confounding. Modification of the suicidereligiosity association on the type of country analysed (countries with low versus those with high levels of religiosity respectively) was apparent after adjustment for socioeconomic variation but for men only ( $F$ value for interaction $=5.6(\mathrm{df} 1,25) ; \mathrm{p}=0.026)($ table 2$)$ so that, for them, a negative ecological association between religiosity and suicide rates was apparent in the less but not in the more religious countries (fig 1 ).

Adjusted for socioeconomic variation, negative associations between suicide rates and religiosity were most pronounced for the elderly and women and, for men, apparent in the 13 least religious countries only (table 3 ).

Table 3 Religiosity and sex specific suicide rates; 26 countries, 1986-90, adjusted for socioeconomic confounding and stratified by age group and sample type. Standardised multiple regressions

\begin{tabular}{|c|c|c|c|c|}
\hline & & \multicolumn{3}{|c|}{ Age and region specific adjusted estimates regression coefficient, $p$ value } \\
\hline \multicolumn{2}{|c|}{ Standardised independent variables } & $\begin{array}{l}\text { Male suicide rates } \\
\text { Sample } 1\end{array}$ & Sample 2 & $\begin{array}{l}\text { Female suicide rates } \\
\text { Foint sample }(n=26)\end{array}$ \\
\hline \multirow[t]{3}{*}{$15-29$} & religiosity $^{a}$ & $\begin{array}{l}-0.05(-0.63 \text { to } 0.53) \\
0.850\end{array}$ & $\begin{array}{l}0.41(-0.25 \text { to } 1.07) \\
\mathrm{p}=0.198\end{array}$ & $\begin{array}{l}-0.17(-0.46 \text { to } 0.11) \\
0.226\end{array}$ \\
\hline & summary confounder & $0.27(-0.35$ to 0.89$)$ & $0.41(0.09$ to 0.74$)$ & $0.34(0.05$ to 0.62$)$ \\
\hline & & 0.352 & 0.020 & 0.024 \\
\hline $30-59$ & religiosity $^{\mathrm{b}}$ & $\begin{array}{l}-0.37(-1.03 \text { to } 0.29) \\
0.239\end{array}$ & $\begin{array}{l}0.24(-0.32 \text { to } 0.80) \\
0.366\end{array}$ & $\begin{array}{l}-0.12(-0.38 \text { to } 0.14) \\
0.346\end{array}$ \\
\hline \multirow[t]{2}{*}{$60+$} & religiosity $^{\mathrm{c}}$ & $\begin{array}{l}-0.61(-1.34 \text { to } 0.12) \\
0.093\end{array}$ & $\begin{array}{l}-0.14 \text { ( }-0.58 \text { to } 0.29) \\
0.485\end{array}$ & $-0.31(-0.60$ to -0.31$)$ \\
\hline & summary confounder & $\begin{array}{l}0.25(-0.53 \text { to } 1.03) \\
0.495\end{array}$ & $\begin{array}{l}0.35(0.14 \text { to } 0.57) \\
0.005\end{array}$ & $\begin{array}{l}0.51(0.23 \text { to } 0.79) \\
0.001\end{array}$ \\
\hline
\end{tabular}

Estimates of regression coefficients for religiosity adjusted for the separate five confounders. ${ }^{a}$ Men (sample 1$)-0.09$ ( -0.85 to 1.03 ); men (sample 2) 0.38 ( -0.27 to 1.04$)$; women -0.17 ( -0.43 to 0.08 ). ${ }^{\mathrm{b}} \mathrm{Men}$ (sample 1$)-0.36$ ( -1.38 to 0.66 ); men (sample 2 ) 0.28 $(-0.33$ to 0.88$)$; women -0.14 ( -0.41 to 0.13 ). ${ }^{c}$ Men (sample 1$)-0.84(-2.01$ to 0.32$)$; men (sample 2$)-0.08$ ( -0.59 to 0.42 ); women $-0.34(-0.59$ to -0.08$)$. 
Discussion

Consistent with existing evidence, ${ }^{2} 679-13$ there were strong negative linear associations between aggregate levels of religion and suicide rates. These were stronger for women and the elderly than for men and the young, and largely attributable to confounding by socioeconomic variation. The complete removal of the overall association of male suicide rates with religiosity after adjustment for confounding is probably attributable to the extent to which socioeconomic differences were controlled for, no previous studies having adjusted for five different potential confounders simultaneously.

Despite absence of an overall adjusted association between religiosity and male suicide rates, stratification of the sample according to exposure levels revealed contrasting patterns in the two subsamples with negative associations in the least and positive (although not significantly so) ones in the more religious nations. Ecological effect modification is the most likely explanation for this but other possibilities need consideration. Ecological confounding - that is, variation of suicide rates between countries for reasons unrelated to religiosity-may also affect the slope of the regression line. When confounding is present alongside effect modification, the net effect may be to increase curvilinearity, or to decrease or even obscure it. However, the variation of regression coefficients for male suicide is unlikely to be attributable to residual confounding for the following reasons. Adjustment was not limited to one or two confounders but based on five separate indicators obtained from different sources. Secondly, by using a multivariate summary confounder score the problem of controlling for many confounders simultaneously was alleviated and adjustment therefore likely to have been more efficient, especially in the age stratified analyses based on small numbers of rates. ${ }^{33}$

The possibility also has to be considered that "overadjustment" may, artificially, introduce curvilinearity. However, this is unlikely to account for the curved shape of adjusted regression line for male suicide rates because analyses using the summary confounder score (constraining the association between suicide rates and confounders to be on a straight line) were similar to those using the separate confounders. In ecological studies, lacking data on individual exposure status, there can be no complete certainty about whether or not confounding is adequately controlled for. Some may argue that other variables, such as alcohol consumption levels ${ }^{8}$ should have been included while others may consider it inappropriate to adjust for variables such as divorce or birth rates, which may be intermediaries between religion and suicide. Within the constraints of these analytical imponderables, the most convincing support for ecological effect modification as the responsible mechanism for the curved regression line for male suicide rates derives from its good fit with other evidence. A similar curvilinearity has been demonstrated, independently, for the same association across Dutch provinces where
KEY POINTS

- Ecological research that does not consider ecological effect modification and cross cultural variation of relative risks, may yield uninterpretable results.

- The prevalence of religiosity modifies the strength of its own ecological association with male, but not female suicide rates across 26 countries.

- Especially where psychosocial variables are concerned, the exposure's prevalence is likely to affect the slope of ecological regression lines.

- At the micro-level, this may manifest itself as dependence of risk in exposed people on the exposure's prevalence locally.

- Relative risks in psychiatric epidemiology have little meaning outside the study groups in which they were originally found to apply.

socioeconomic differences are small and unlikely to affect the slope of the regression line. ${ }^{23}$ The association between suicide acceptability and religiosity in men, but not women, is modified by levels of religiosity in respondents' countries providing direct evidence of effect modification taking place between the variable under study here and an individual level proxy for suicidal behaviour. ${ }^{22}$

This study certainly has limitations. The outcome variable, officially recorded suicide, is subject to reporting biases that may relate with religion's national dominance. ${ }^{35}$ However, this cannot account for the age and sex differences. Furthermore, its effect would be expected to be most pronounced in the most religious countries-in contrast with the male pattern observed. Extrapolation from WVS samples to entire nations depends on sampling methods and sample sizes. Despite its scale, care was taken in WVS to ensure unbiased sampling ${ }^{29}$ - the availability of individual sampling scores enhanced the reliability of aggregate values. Weighting for sample sizes did not affect regression coefficients supporting the reliability of the aggregate values. Furthermore, the ranking of countries according to religious score is comparable to rankings published by others who used different methods. ${ }^{36}$ While the extent of missing values in WVS was small, proportions of missing socioeconomic scores were high for some countries whose summary scores had to be imputed using nonmissing values. However, this hardly affected regression coefficients so that resulting bias is unlikely. To facilitate comparison of effect size for different independent variables, these were standardised. Although the use of standardised regression coefficients has been criticised, ${ }^{37}$ their use in the present analysis is valid as the standard deviations used to obtain the standardised measures apply all to the same sample. Moreover, analytical decisions were based, not on the size of regression coefficients, but on measures of statistical significance that are unaffected by standardisation. 
When ecological confounding and effect modification are not present or controlled for, the slope of the regression line is proportional to the relative risk or-in case of negative regression coefficients-relative protection. ${ }^{15}$ Given the extent of control for socioeconomic confounding and, for the male suicide rates, stratification of the sample by an ecological effect modifier, it can be argued that these conditions are met so that, as indicated in figure 1 , comparable individual levels of religious belief are a protective factor against male suicide in less religious countries but not in more religious ones. A variety of individual level mechanisms may underlie this type of effect. At reducing prevalence of risk or protective factors, psychological differences between the exposed minority and the non-exposed majority are likely to be larger because of social selection. Minority groups may suffer marginalisation while, conversely, increased levels of intragroup social support in small, close knit groups may outweigh adverse effects of reduced integration in the majority. ${ }^{38}$ Individual level research indicates the likely relevance of this type of contextual effect for many psychosocial risk factors ${ }^{818-20} 2238$ and suggests that it may affect men more than women. ${ }^{21} 2239$ Future multi-level studies are needed, ${ }^{14}$ to confirm whether male and female suicide (or other ill health) risks given certain degrees of exposure, relate differently to higher level characteristics such as peer group norms and community characteristics. ${ }^{40}$

This study generates interesting hypotheses and has theoretical implications for prevention and research in social psychiatry. Individual level inferences from ecological associations have given ecological research a poor reputation. ${ }^{41}$ However, when macro-level consequences of ecological effect modification are considered, patterns surface with potential public health importance. The relative impact of reduction of risk, or increase of protective factors, on suicide rates, will vary from community to community. Reduction of risk factor prevalence may lead to concentrating risk in those, the most vulnerable, who are beyond reach by such programmes. Relative risks, lists of which tend to be published, ${ }^{42}$ should not be applied outside original study populations and only be used cautiously to estimate the likely impact of risk factor reduction on aggregate outcomes such as suicide rates. ${ }^{43}$ Ecological effect modification is often considered as a methodological nuisance ${ }^{16}$ but demonstration of its relevance for given risk factors may guide individual level research to explore sociocultural processes that may differ between the sexes and modify effects of exposure to risk.

Funding: The Wellcome Trust.

Conflicts of interest: none

This work was done at the Department of Psychological Medicine, Institute of Psychiatry, London SE5 8AZ where JN was cine, Institute of Psychiatry, London SE5 8AZ where JN was supported by a Wellcome Training Fellowship in Epidemiology.
Thanks are due to the ESRC Data Archive, University of Essex, Colchester, for providing access to the WVS data.
1 LaVecchia C, Lucchini F, Levi F. Worldwide trends in suicide mortality, 1955-1989. Acta Psychiatr Scand suicide mortalicy

2 Durkheim E. Suicide; a study in sociology. [Translated by JA Spaulding and G Simpson]. Illinois: Free Press, 1951.

3 Yang B, Lester D. Time series analyses of the American suicide rate. Soc Psychiatry Psychiatr Epidemiol 1990;25:274-5.

4 Pritchard C. New patterns of suicide by age and gender in the United Kingdom and the Western World 1974-1992; an indicator of social change? Soc Psychiatry Psychiatr Epidemiol 1996;31:227-34.

5 Wasserman IM. A longitudinal analysis of the linkage between suicide, unemployment and marital dissolution. fournal of Marriage and the Family 1984;46:853-9.

6 Stack S. The effect of religious commitment on suicide; a cross-national analysis. F Health Soc Behav 1983;24:36274.

7 Kerkhof A, Kunst A. A European Perspective on Suicidal Behaviour. In: Jenkins R, Griffiths S, Wylie I, et al, eds. The prevention of suicide. London: HMSO, 1994:22-33.

8 Nortstrom T. Alcohol and suicide; a comparative analysis of France and Sweden. Addiction 1995;90:1463-90.

9 Diekstra RFW. Suicidal behaviour in children and young adults; the international picture. Crisis 1989;10:16-35.

10 Stack S. Religion and suicide; a reanalysis. Soc Psychiatry 1980;15:65-70.

11 Pescosolido BA. The social context of religious integration and suicide; pursuing the network explanation. Sociological Quarterly 1990;31:337-57.

12 Breault KD. Suicide in America: A test of Durkheim's theory of religious and family integration, 1933-1980. Am f Sociol 1986;92:628-56.

13 Trovato F. A Durkheimian analysis of youth suicide: Canada, 1971 and 1981. Suicide Life Threat Behav 1992;22:413-27.

14 Morgenstern H. Ecologic studies. In: Rothman KJ, Greenland S, eds. Modern epidemiology. Philadelphia: Lippincott-Raven, 1998:459-80.

15 Beral V, Chilvers C, Fraser P. On the estimation of relative risk from vital statistical data. $\mathcal{F}$ Epidemiol Community risk from vital statistica

16 Greenland S, Morgenstern H. Ecological bias, confounding and effect modification. Int $\mathcal{F}$ Epidemiol 1989;18:269-74.

17 Breslow NE, Day NE. Statistical methods in cancer research. Vol 1 - The analysis of case-control studies. Lyon: IARC, 1980.

18 Brown GW, Prudo R. Psychiatric disorder in a rural and an urban population. (1) etiology of depression. Psychol Med 1981;11:581-99.

19 Platt S, Kreitman N. Trends in parasuicide and unemployment among men in Edinburgh, 1968-1982. BMF 1984;289:1029-32.

20 Leenstra AS, Ormel J, Giel R. Positive life change and recovery from anxiety and depression. $B r \quad \mathcal{F}$ Psychiatry 1995; 166:333-43.

21 Deavoll BJ, Mulder RT, Beautrais AL, et al. One hundred years of suicide in New Zealand. Acta Psychiatr Scand 1993;87:81-85

22 Neeleman J, Halpern D, Leon D, et al. Tolerance of suicide, religion and suicide rates; an ecological and individual-level study in 19 western countries. Psychol Med 1997;27:116571 .

23 Neeleman J. Regional suicide rates in the Netherlands; does religion still play a role? Int f Epidemiol 1998;27:466-72.

24 Levin JS, Vanderpool HY. Is religion therapeutically significant for hypertension? Soc Sci Med 1989;29:69-78.

25 Zuckerman DM, Kasl SV, Ostfeld AM. Psychosocial predictors of mortality amongst the elderly poor. Am $\mathcal{F}$ Epipredictors of mortality an
demiol $1984 ; 119: 410-23$.

26 World Values Study Group. World Values Survey (1981-1984 and 1990-1993) computer file. ICPSR version. Ann Arbor: ICPSR, 1994

27 Crombie IK. Trends in suicide and unemployment in Scotland, 1976-1986. BMF 1989;298:782-4.

28 Neeleman J. The social and epidemiological context of suicidal behaviour. [PhD thesis]. Groningen: University of Groningen, 1997

29 Halman L, De Moor R. Comparative research on values. In: Ester P, Halman L, De Moor R, eds. The individualizing society; value shift in Europe and North America. Tilburg: Tilburg University Press, 1994:21-36.

30 World Health Organization. Health statistical data collections (mortality files). Geneva: WHO, 1992.

31 Roberts E. Working document; improvement of the basic data: facing the lessons of ICD-9. Caracas: PAHO, 1994.

32 World Bank. World Bank Development Report; development and environment. Oxford: Oxford University Press, 1992.

33 Rothman KJ. Modern epidemiology. Boston: Little, Brown, 1986

34 Stata Corporation. Stata release 5.0. College Station, Texas: Statacorp, 1997

35 Neeleman J, Wessely S. Changes in classification of suicide in England and Wales; time trends and associations with coroners' professional background. Psychol Med 1997;27: 467-72.

36 Halman L, De Moor R. Religion, churches and moral values. In: Ester $\mathrm{P}$, Halman $\mathrm{L}$, De Moor $\mathrm{R}$, eds. The individualizing society; value change in Europe and North America. Tilburg: Tilburg University Press, 1994:3765.

37 Greenland S, Schlesselman JJ, Criqui MH. The fallacy of employing standardized regression coefficients and correlaions as measures of effect. Am 7 Epidemiol 1986;123:203 
38 Halpern D. Minorities and mental health. Soc Sci Med 1993;36:597-607.

39 Brugha TS, Bebbington PE, MacCarthy B, et al. Gender, social support and recovery from depression. Psychol Med 1990;20:147-56.

40 Borges G, Anthony JC, Garrison CZ. Methodological issues relevant to epidemiologic investigations of suicidal behaviour in adolescents. Epidemiol Rev 1995;17:228-39.
41 Kasl SV. Mortality and the business cycle: some questions about research strategies when utilizing macrotions about research strategies when utilizing macro$784-8$.

42 Gunnell D, Frankel S. Prevention of suicide: aspirations and evidence. BMF 1994;308:1227-33.

43 Lewis G, Hawton K, Jones P. Strategies for preventing suicide. Br f Psychiatry 1997;171:351-4. 